\title{
ESTUDO CONTRASTIVO DOS ACÓRDÃOS DOS SUPREMOS TRIBUNAIS DE PORTUGAL E DO BRASIL: IMPLICAÇÕES PARA A TRADUÇÃO
}

\author{
Janine Pimentel
}

\section{Introdução}

Apesar do conceito de gênero textual fazer parte, desde há muito tempo, dos critérios para a constituição de grandes corpora que pretendem retratar a chamada "língua geral", só mais recentemente é que ele foi aplicado ao estudo da tradução especializada e à terminografia. No entanto, alguns trabalhos têm mostrado que o estudo das convenções associadas aos gêneros textuais utilizados por uma dada comunidade discursiva e o estudo contrastivo desses mesmos gêneros, tal como eles são usados por duas ou mais comunidades discursivas, podem ser úteis para tradutores, teóricos da tradução e terminológos. Por exemplo, as decisões judiciais são um gênero textual que tem interessado alguns pesquisadores na área da análise do discurso e na área da tradução (Bhatia, 1993; Stolze, 2010). Ainda que as características principais deste gênero estejam bem documentadas e tenham sido utilizadas para o auxílio da tradução, as aplicações desses resultados em terminografia, nomeadamente à criação de bancos de termos, têm sido mais escassas.

O nosso interesse pelo conceito de gênero textual, em geral, e pela decisão judicial, em particular, prende-se com o facto de estarmos a desenvolver, desde há alguns anos, um banco de termos multilíngue (português, inglês, francês) que pretende descrever a terminologia das decisões judiciais. A versão portuguesa baseia-se num corpus de decisões do Supremo Tribunal de Justiça de Portugal (STJ) e, recentemente, criou-se um corpus das decisões do Supremo Tribunal Federal do Brasil (STF) para estudar as diferenças entre a terminologia jurídica portuguesa e a terminologia jurídica brasileira. As conclusões a tirar dessa pesquisa, ainda em andamento, podem ajudar a perceber a forma como o português do Brasil (PB) pode ser integrado nessa base de dados. Será necessário criar uma nova versão só para o PB? Ou o repertório do português europeu (PE) poderá acolher as eventuais variantes terminológicas sem que seja necessário criar um novo repertório?

Esta contribuição pretende responder a uma parte destas perguntas. Assim, começaremos por rever os trabalhos anteriores que sublinham a importância dos gêneros textuais para a tradução e para a terminologia bem como os estudos comparativos de decisões judiciais que já foram feitos. De seguida, examinaremos as características dos textos 
PIMENTEL - Estudo contrastivo dos acórdãos dos Supremos Tribunais...

produzidos pelo STJ e pelo STF. Por fim, levantaremos as implicações que os resultados da análise contrastiva trazem para a tradução bem como para o desenvolvimento do nosso trabalho.

\section{Gêneros textuais, tradução e terminologia}

Em função dos objetivos do estudo acima descritos podemos agrupar os autores que têm reconhecido a importância do conceito de gênero textual para as suas pesquisas em duas categorias. O primeiro grupo é aquele que aplica este conceito ao estudo da tradução especializada: Borja Albi (2013), Reiss (2009), Stolze (2010), entre outros. Por exemplo, estas autoras oferecem várias razões pelas quais a organização dos textos de partida em função do gênero textual é útil para os estudos da tradução. Uma delas é a noção de convenção, associada à de gênero textual, pois esta condiciona o léxico, a gramática, a fraseologia, a estrutura e até mesmo a pontuação de um dado gênero de texto. Borja Albi (2013) tem mesmo usado a noção de gênero textual não só como ferramenta epistemológica para categorizar e analisar o fenômeno da tradução especializada, mas também usa os resultados dessa análise para refletir sobre a melhor maneira de construir bases de dados para tradutores.

O segundo grupo é aquele que tem refletido sobre a importância dos gêneros textuais para a criação adequada de corpora de especialidade bem como para a subsequente análise e interpretação dos dados que se extraem destes. Aqui destacamos Aussenac-Gilles e Condamines (2007), Condamines (2008) e Rogers (2000). Aussenac-Gilles e Condamines (2007, p. 140) explicam que a noção de gênero textual pode ser usada por terminólogos que trabalham com corpora para descrever a terminologia, na medida em que determinados gêneros textuais são típicos de determinados discursos de especialidade. Indo mais longe, Rogers (2000) defende que este conceito tem uma função classificatória importante para a organização de corpora e a subsequente interpretação da sua terminologia. Esta ideia é visível também nos trabalhos que mencionaremos em seguida.

\section{Estudos contrastivos de acórdãos}

As decisões judiciais têm sido amplamente estudadas sobretudo por pesquisadores da teoria do gênero. Por exemplo, Bhatia (1993) e Maley (1985) concentraram-se na macroestrutura das decisões judiciais, na realização dos objetivos comunicacionais destas por meios linguísticos, e nas suas características intertextuais. Na área da tradução, Stolze (2010, 
PIMENTEL - Estudo contrastivo dos acórdãos dos Supremos Tribunais...

p. 19) afirma, com razão, que uma estrutura textual estandardizada facilita a compreensão por parte dos intervenientes num ato de comunicação. Só que as normas dessa estrutura têm como pano de fundo uma dada cultura, o que requer uma tradução literal ou uma adaptação à cultura de chegada. Assim, as decisões judiciais alemãs apresentam, logo no início, a parte decisória em uma frase e desenvolvem-se com a descrição dos factos e os fundamentos da decisão como em jeito de justificação do veredicto. As decisões francesas começam com a descrição dos fatos, procedem com os fundamentos da decisão juntamente com uma lista de legislação relevante, e terminam com a parte decisória. $\mathrm{Na}$ Itália, depois de uma exposição das conclusões dos advogados, as decisões descrevem o percurso do processo como prova de legitimidade legal do caso, apresentam os fundamentos da decisão e terminam com a parte decisória.

Outros estudos que têm comparado este gênero textual numa escala interlinguística a fim de ajudar os tradutores são os de Engberg (1997) e Vesterager (2010). O primeiro comparou as convenções linguísticas e textuais das decisões judiciais alemãs e dinamarquesas, nomeadamente as ocorrências de atos performativos nestes textos, mostrando a pertinência deste tipo de informação para a escolha de equivalentes. Por sua vez, Vesterager (2010) levou a cabo um estudo contrastivo sobre a estrutura e as estratégias retóricas das decisões dinamarquesas e espanholas. Foram identificadas várias semelhanças:

For instance both languages use legal terminology to help place the judgment in its proper context, and their choice of verbs and grammatical tense supports the purpose of the moves. Moreover, in order to be able to express something of general validity, both languages prefer the impersonal writing style. Furthermore, in Danish as well as in Spanish the conclusion of the judgment is traditionally initiated by a standard formula [...]. (Vesterager, 2010, p. 221)

Todavia, a comparação entre as decisões dinamarquesas e espanholas também revelou diferenças. Por exemplo, na secção inicial dos textos, as decisões dinamarquesas incluem partes maiores de co-texto, enquanto que as decisões espanholas incluem a conclusão tirada pelo tribunal anterior. Na parte final, as decisões espanholas incluem mais informação do que as dinamarquesas, tais como as possibilidades de recurso, o pagamento da taxa do advogado e a confirmação da decisão. As principais diferenças entre os textos residem na sintaxe (comprimento das frases, subordinação, etc.) e no léxico (terminologia e variação lexical). De acordo com a autora, são estas as diferenças que criam impasses na tradução deste gênero de textos. 
Ainda que sejam vários os estudos que têm caracterizado o gênero textual que é a decisão judicial, a verdade é que poucos são aqueles que se concentraram no subgênero da decisão que é o acórdão. Para além disso, a maioria dos trabalhos existentes comparam ou decisões produzidas por juízes oriundos de sistemas linguísticos diferentes mas que trabalham em sistemas jurídicos similares, ou decisões produzidas por juízes oriundos de sistemas linguísticos e jurídicos diferentes. Esta pesquisa difere destas últimas na medida em que compararemos um subgênero de decisões produzidas por juízes que trabalham em sistemas jurídicos e linguísticos comparáveis.

\section{O corpus}

Como mencionado anteriormente, encontramo-nos atualmente a desenvolver um banco de terminologia cuja descrição dos dados se baseia na observação dos termos in vivo, i.e. tal como eles ocorrem num corpus. Trata-se de um corpus comparável ao qual foram adicionados textos da mais alta instância de tribunais de Portugal e do Brasil (Tabela 1). O subcorpus do PE contém atualmente dois milhões e meio de formas de palavras (tokens), enquanto que o subcorpus do PB contém apenas trezentas mil. Como podemos observar a partir da Tabela 1, o acórdão brasileiro é, em média, três vezes mais curto do que o acórdão português.

\begin{tabular}{|l|c|c|}
\cline { 2 - 3 } \multicolumn{1}{c|}{} & Português Europeu & Português do Brasil \\
\hline Tokens & 2500000 & 315000 \\
\hline Textos & 400 & 150 \\
\hline $\begin{array}{l}\text { Tokens por } \\
\text { texto }\end{array}$ & 6500 & 2100 \\
\hline Datas dos textos & 2009 & 2012,2013 \\
\hline
\end{tabular}

Tabela 1. Corpus comparável do português.

Para avaliarmos as diferenças e semelhanças entre os textos portugueses e brasileiros e respondermos às perguntadas anteriormente formuladas, decidimos analisar as características destes textos à luz dos elementos habitualmente tidos em conta na literatura, nomeadamente a função do texto, o seu contexto institucional, o seu emissor e macroestrutura. 
PIMENTEL - Estudo contrastivo dos acórdãos dos Supremos Tribunais...

\section{Os acórdãos do Supremo Tribunal de Portugal}

O termo "acórdão" deriva da terceira pessoa do plural do verbo acordar e é usado no início e no final dos textos para marcar o acordo manifesto na decisão tomada pelo coletivo de juízes. Um acórdão difere de uma sentença na medida em que esta pode ser decidida por apenas um juiz que trabalha nas instâncias inferiores, enquanto que o acordão resulta sempre da decisão de um coletivo de juízes. Todos os acórdãos que fazem parte do corpus utilizado nesta pesquisa foram produzidos pelo STJ e selecionados a partir da base de dados do Instituto das Tecnologias de Informação na Justiça do Departamento de Justiça de Portugal.

\section{Função}

Um acórdão é uma decisão tomada pela mais alta instância de tribunais de Portugal relativamente a uma matéria que só pode ser julgada naquele tribunal. Ele pode também ser a revisão de uma decisão tomada anteriormente por outro tribunal. Em todos os casos, ele é sempre escrito e divulgado para benefício das partes envolvidas no processo, para os professionais do direito, nomeadamente outros juízes. Ainda que eles possam abrir um precedente e ser vinculativos nos tribunais inferiores, não há nenhum regulamento em Portugal que defina essa função dos acórdãos.

\section{Contexto institucional}

A divisão judiciária portuguesa comporta 3 instâncias, contando-se 4 distritos judiciais (Porto, Coimbra, Évora e Lisboa), 58 círculos judiciais e 227 comarcas que são as menores unidades jurisdicionais. Os tribunais judiciais exercem jurisdição cível e criminal em todas as áreas e matérias não atribuídas a outras ordens judiciais. O órgão superior é o STJ que tem sede em Lisboa. Tanto o STJ quanto os tribunais de Relação (abaixo do STJ) comportam divisões em três secções: cível, penal e social. A competência do STJ não interfere com a competência do Tribunal Constitucional. De acordo com Prata (2005) o STJ é competente para: julgar recursos judiciais das decisões das secções criminais; julgar recursos judiciais das decisões tomadas pelos tribunais de primeira instância; uniformizar a jurisprudência; julgar delitos praticados pelo Presidente da República, pelo Presidente da Assembleia da República, pelo Primeiro Ministro, pelos juízes Conselheiros, pelos juízes dos tribunais de Relação e pelos magistrados do Ministério Público, no exercício de suas funções. 


\section{Emissores}

O STJ tem atualmente um juiz presidente e 22 juízes chamados "Juízes Conselheiros". O presidente do STJ é a quarta figura na hierarquia do estado português, a seguir ao Presidente da República, ao Presidente da Assembleia da República e ao Primeiro Ministro. Todos os textos do corpus do PE foram redigidos pelos juízes do STJ. Mais especificamente, os acórdãos são redigidos por um juiz chamado "Relator" e assinados pelo coletivo de juízes. O papel dos juízes no sistema judicial português consiste em descobrir e aplicar a lei a um dado caso. O juiz português pode ser visto como sendo la bouche de la loi, pois é a entidade interpretativa que toma decisões objetivas (Castanheira Neves, 2008) baseadas na doutrina e na legislação, as principais fontes do direito português que faz parte da mesma família do sistema jurídico continental. Assim, apesar da jurisprudência ser levada em conta nas decisões judiciais, estas não têm o mesmo peso vinculativo como elas têm, por exemplo, no sistema da common law.

\section{Macroestrutura}

Na sua forma escrita, o acórdão é composto por três secções: uma identificação, um sumário e uma parte temática. A secção chamada "Identificação" contém a informação que permite identificar o documento fisicamente, por exemplo numa base de dados. Normalmente, encontramos aqui o código de identificação do acórdão, o número do acórdão, o nome do juiz responsável pela elaboração do acórdão, os termos de indexação, a data do texto, o tipo de voto que aquela decisão recebeu, o grau de confidencialidade, o tipo de recurso e a decisão final. Podemos também encontrar, nalguns textos, uma lista de referências bibliográficas usadas pelos juízes que costumam estar organizadas em três categorias: doutrina, códigos e jurisprudência.

A secção chamada "Sumário" encontra-se logo após a secção da identificação. É aqui que o juiz faz um resumo dos pontos essenciais do acórdão. A "Parte temática" é organizada em três divisões: o relatório, os fundamentos e a decisão. Estas três divisões devem estar separadas de forma clara e são introduzidas no texto ou por numerais romanos ou por cabeçalhos. Em todos os casos, a parte temática é precedida pela frase "Acordam no Supremo Tribunal de Justiça" assinalando esta que a descrição factual e historial do caso é conhecida pelos juízes. O "Relatório" descreve os fatos do processo, as matérias de direito que estão a ser discutidas entre as partes e os princípios factuais e legais nos quais a decisão será baseada. Por sua vez, os "Fundamentos" apresentam a análise levada a cabo pelos juízes no que diz respeito às questões factuais e legais enumeradas e relatadas no relatório. A base lógica da 
PIMENTEL - Estudo contrastivo dos acórdãos dos Supremos Tribunais...

decisão bem como as razões que determinam a decisão dos juízes encontram-se aqui mencionadas. Finalmente, na "Decisão", o juiz responde às perguntas levantadas pelas partes no processo fechando o silogismo desenvolvido nas secções anteriores. As decisões podem ser favoráveis ou não para o autor do pedido ou do recurso, a figura processual que desencadeou o processo na justiça.

\section{Os acórdãos do Supremo Tribunal Federal do Brasil}

Tal como em Portugal, no Brasil o termo "acórdão" também deriva da terceira pessoa do plural do verbo acordar que aparece no início da secção chamada "acórdão" logo após a “ementa" (resumo da decisão). Todos os acórdãos que fazem parte do corpus utilizado nesta pesquisa foram produzidos pelo STF e selecionados a partir da base de dados do STF disponível no site www.stf.jus.br.

\section{Função}

Um acórdão é uma decisão tomada pela mais alta instância de tribunais do Brasil e é sempre escrito e divulgado para benefício das partes envolvidas no processo, para os professionais do direito, nomeadamente outros juízes. O conjunto de acórdãos forma a jurisprudência brasileira. De acordo com Guimarães (2004):

[...] o acórdão se enquadra no âmbito dos atos normativos (ou deliberativo-normativos), ou seja, aqueles oriundos de deliberações de órgãos da administração pública (geralmente colegiados), que trazem regras e normas de cumprimento. Observa-se ainda, no acórdão, a preponderância do valor administrativo sobre o histórico, pois tem como função precípua manifestar uma determinada prestação jurisdicional em uma determinada lide [...]. (Guimarães 2004, p. 34)

\section{Contexto institucional}

O STF é o órgão máximo da justiça brasileira e tem como função principal zelar pelo cumprimento da Constituição. Abaixo dele está o Superior Tribunal de Justiça (STJ), responsável por fazer uma interpretação uniforme da legislação federal. O STF, com sede em Brasília e jurisdição sobre todo o território nacional, é composto por onze Ministros escolhidos pelo Presidente da República. Para além de exercer o controle da constitucionalidade das leis, o STF pode julgar o Presidente da República, o Vice-Presidente, os membros do Congresso, os seus Ministros e o Procurador-Geral da República por delitos comuns em matéria criminal. Uma vez que o STF não julga questões de fato ou questões de direito local, tirando algumas exceções, para se obter a prestação jurisidicional do STF, o 
PIMENTEL - Estudo contrastivo dos acórdãos dos Supremos Tribunais...

recorrente deve enquadrar a sua pretensão em questões de direito federal. Finalmente, o STF também é responsável por expedir súmulas de jurisprudência constitucional (resumos do pensamento reiterado dos tribunais) com efeitos vinculantes para toda a estrutura dos órgãos do poder judiciário nacional (Theodoro Júnior, 2014).

\section{Emissores}

Aos juízes do STF cabe-lhes decidir de acordo com a lei, adaptando racionalmente a fórmula genérica abstrata ao caso concreto. Para tal, procedem a um conjunto de pesquisas, raciocínios e argumentos, visando a delimitação específica do fato que será apreciado bem como as normas jurídicas aplicável ao mesmo. De acordo com Theodoro Júnior (2014, p. 248), “a missão do juiz não é [...] apenas a de reproduzir, na composição da lide, a regra editada pelo legislador. Incumbe-lhe também uma atividade criativa, para completar o preceito legal genérico e pouco detalhado, assim como para suprir-lhe as lacunas."

\section{Macroestrutura}

A doutrina processual brasileira aponta para dois tipos de critérios a serem observados na redação de sentenças e acórdaos: os critérios subjetivos e os critérios objetivos (Guimarães, 2004). Apesar de não existirem na lei fórmulas ou normas específicas para a redação de sentenças e acórdãos, os chamados "requisitos subjetivos" preconizam que os acórdãos sejam redigidos de maneira clara e concisa. Por sua vez, os requisitos objetivos, encontram-se especificamente previstos no art. 458 do Código de Processo Civil:

I - o relatório, que conterá o nome das partes, a suma do pedido e da resposta do réu, bem como o registro das principais ocorrências havidas no andamento do processo;

II - os fundamentos, em que o juiz analisará as questões de fato e de direito;

III - o dispositivo, em que o juiz resolverá as questões que as partes lhe submeteram.

A estrutura de um acórdão contém necessariamente elementos de duas ordens: descritivos (ou de identificação) e temáticos (ou de conteúdo). Os elementos descritivos do acórdão incluem: o nome do tribunal que confere o acórdão; a turma que julgou o recurso; o nome do Juiz Relator, os nomes das partes, a natureza e número do recurso que lhe deu origem; o número do acórdão e a instância julgadora inferior cuja decisão é objeto de interposição do recurso.

A seguir aos elementos descritivos localizam-se a ementa e o acórdão (elementos temáticos). A "Ementa” é uma síntese dos tópicos que estavam em julgamento e apresenta-se, 
PIMENTEL - Estudo contrastivo dos acórdãos dos Supremos Tribunais...

normalmente, sob a forma de termos de indexação e frases numeradas. O "Acórdão" é a decisão tomada pelo colegiado de juízes e não costuma ter mais do que um parágrafo. Esta primeira parte dos elementos temáticos é bastante condensada, pelo que é desenvolvida na parte seguinte do texto. É na segunda parte do documento que encontramos, então, o relatório, o voto e a decisão. O "Relatório" é uma representação histórica do processo em que o juiz recupera, de forma sintética, os pontos essenciais da controvérsia (a questão em causa bem como seu trâmite enquanto processo), ainda não manifestando especificamente seu ponto de vista. O "Voto" é o processo de análise em que as questões fáticas e jurídicas afloradas passam por um crivo analítico (por meio de um conjunto de operações lógicas), apreciando-se as controvérsias à luz do ordenamento jurídico vigente. Finalmente, o "Dispositivo" é a resolução por parte do juiz das questões que lhe foram apresentadas pelas partes.

\section{Comparação e implicações para a tradução}

Um dos aspectos que aproximam este gênero textual, tal como ele é produzido pelas duas comunidades de especialistas, é a distinção conceptual que ele pressupõe entre acórdão e sentença. Em Portugal e no Brasil, o termo "acórdão", que dá nome a este gênero de texto, deriva da terceira pessoa do plural do verbo acordar, verbo usado também para marcar o acordo na decisão tomada por um coletivo de juízes. Todavia, enquanto que em Portugal este verbo ocorre no início e no final dos textos, no Brasil ele só ocorre no início. Numa situação de tradução, é necessário entender que esta fórmula é característica deste género textual e decidir se ela pode ser mantida ou não.

Provavelmente o principal aspecto de dissemelhança identificado na análise das características dos textos é o contexto institucional em que eles são produzidos. Na verdade, o STJ e o STF não são entidades totalmente equivalentes pois os sistemas judiciais estão organizados de forma diferente. Em Portugal, o STJ é um órgão independente do Tribunal Constitucional que julga questões de constitucionalidade independentemente de litígios concretos. No Brasil, o STF não só assume competências típicas de um tribunal de última instância, como o STJ em Portugal, mas também de um Tribunal Constitucional. Tal diferença pode ter repercussões sobre as matérias abordadas nos acórdãos e consequentemente sobre a terminologia. Assim, os tradutores terão provavelmente que recorrer a dicionários, glossários ou bancos de dados que incluam vários subdomínios do direito, com destaque para o direito constitucional no caso dos acórdãos brasileiros. 
PIMENTEL - Estudo contrastivo dos acórdãos dos Supremos Tribunais...

Os diferentes contextos institucionais e o papel mais "criativo" desempenhado pelos juízes brasileiros podem explicar também as diferenças na macroestrutura e no tamanho dos dois textos. Enquanto que o texto português é constituído por uma secção de identificação, um relatório, fundamentos e uma decisão, o texto brasileiro apresenta a secção de identificação seguida pela ementa e pela decisão, desenvolvendo-as depois no relatório e na secção chamada "voto", dando esta última ênfase aos raciocínios dos diferentes juízes. Todavia, a secção "voto" é marcadamente mais curta do que a secção portuguesa chamada "fundamentos". O conhecimento destas convenções pode orientar a tomada de decisões por parte dos tradutores.

\section{Considerações finais e trabalho futuro}

Depois de passar em revista a literatura sobre a importância dos gêneros textuais e sobre os estudos comparativos de decisões judiciais, fizemos uma análise individual da função, contexto institucional, emissores e macroestrutura dos acórdãos do STJ e STF. A comparação da forma como estes elementos são instanciados em cada subcorpus permite-nos apreender a dimensão das diferenças entre os textos portugueses e brasileiros, diferenças estas que necessitam ser avaliadas na hora de desenvolver um banco de termos que inclua o PE e o PB. Este pequeno estudo aponta para diferenças significativas entre os acórdãos do STJ e do STF por duas razões. Em primeiro lugar, o STF tem funções de controle de constitucionalidade que não são desempenhadas pelo STJ. Em segundo lugar, o papel que os juízes do STF desempenham é mais criativo do que dos colegas portugueses. Sabendo que, no contexto brasileiro, abaixo do STF se encontra o STJ, podemos questionar-nos se este último não corresponderia melhor ao STJ português. Seria, portanto, pertinente adicionar ao corpus do PB as decisões do STJ brasileiro e avaliar, subsequentemente, a comparabilidade da terminologia do corpus europeu e do corpus brasileiro aumentado. Só então se fundamentará melhor a decisão de criar um repertório diferente para o PB, decisão esta apontada pelos resultados que aqui foram descritos.

\section{Agradecimentos}

Gostaríamos de agradecer ao Dr. Francisco Bilac M. Pinto Filho a ajuda preciosa que nos prestou durante a realização deste estudo, e à Profa. Doutora Teresa Dias Carneiro por nos ter posto em contacto com o especialista supracitado.

Este trabalho foi financiado pelo programa PNPD-CAPES 2013. 


\section{Referências}

AUSSENAC-GILLES, Nathalie; CONDAMINES, Anne. Corpus et terminologie. In: PÉDAUQUE, Roger (Ed.). La redocumentarisation du monde. Toulouse: Cepadues Editions, 2007. p. 131-147.

BHATIA, Vijay. Analysing Genre: Language Use in Professional Settings. London: Longman, 1993.

BORJA ALBI, Anabel. A genre analysis approach to the study of the translation of court documents. In: BIEL, Lucja \& ENGBERG, Jan (Orgs.) Lingüística Antwerpiensia 12, 33-53, 2013.

CASTANHEIRA NEVES, António. Digesta. Escritos acerca do Direito, do Pensamento Jurídico, da sua Metodologia e Outros. Coimbra: Coimbra Editora, 2008.

CONDAMINES, Anne. Taking Genre into Account for Analyzing Conceptual Relation Patterns. Corpora v. 3, n. 2, p. 115-140, 2008.

ENGBERG, Jan. Konventionen von fachtextsorten: Kontrastive Analysen zu deutschen und danischen Gerichstsurteilen. Tübingen: Gunter Narr, 1997.

GUIMARÃES, José. Elaboração de ementas jurisprudenciais: elementos teóricometodológicos. Brasília: Editora UnB, 2004.

MALEY, Yon. Judicial Discourse: the Case of Legal Judgment. In: CLARK, John (Ed.). The Cultivated Australian. Hamburg: Buske, 1985. p. 159-175.

PRATA, Ana. Dicionário Jurídico (Direito Civil, Direito Processual Civil, Organização Judiciária). Coimbra: Almedina, 2005.

REISS, Katharina. Problématiques de la traduction. Paris: Economica \& Anthropos, 2009.

ROGERS, Margaret. Genre and Terminology. In: TROSBORG, Anna (Ed.). Analysing Professional Genres. Amsterdam / Philadelphia: John Benjamins, 2000. p. 3-21.

STOLZE, Radegundis. Fachübersetzen - ein Lehrbuch für Theorie und Praxis. Berlin: Frank \& Timme, 2010.

THEODORO JÚNIOR, Humberto. Curso de Direito Processual Civil. Rio de Janeiro: Forense, 2014.

VESTERAGER, Anja. The translation of judgments: An Examination of Potential Translation Challenges in Translating Judgments from Spanish Into Danish. Tese de doutorado, Aarhus University, 2010. 